\title{
Técnicas de coloração para detecção de Encephalitozoon cuniculi em cortes histológicos
}

\author{
Stain techniques for detection of Encephalitozoon cuniculi in tissue sections \\ Maria Anete Lallo ${ }^{I^{*}}$ Eduardo Fernandes Bondan ${ }^{\mathrm{I}}$ José Guilherme Xavier $^{\mathrm{I}}$ \\ Marisa Porta Miche Hirschfeld ${ }^{\mathrm{II}}$
}

\section{- NOTA -}

\section{RESUMO}

No presente trabalho, foram avaliadas diferentes técnicas de coloração aplicadas a cortes histológicos para a identificação de Encephalitozoon cuniculi. Foram utilizados fragmentos hepáticos de camundongos Balb-c, imunossuprimidos com ciclofosfamida e inoculados com esporos de Encephalitozoon cuniculi. Os cortes histológicos incluidos em parafina foram corados pelas técnicas de hematoxilina-eosina (H-E), tricrômica modificada, GramChromotrope, Giemsa, Brown-Hopps, PAS, Ziehl-Neelsen e Grocott, e ainda pela técnica de calcoflúor. As colorações azul de toluidina-fucsina e azul de toluidina foram utilizadas para os cortes incluídos em resina plástica. As técnicas de GramChromotrope, Brown-Hopps e Ziehl-Neelsen foram as que permitiram melhor visualização dos esporos para o diagnóstico de E. cuniculi em cortes histológicos incluidos em parafina, uma vez que possibilitaram a clara diferenciação dos esporos de outras estruturas teciduais. Nos tecidos incluidos em resina plástica, as colorações de azul de toluidina-fucsina e azul de toluidina também facilitaram o encontro do agente. Por outro lado, a técnica tricrômica apresentou grande variabilidade nos resultados, sendo, portanto, pouco indicada para o diagnóstico em tecido. As demais técnicas - H-E, calcoflúor, Grocott, Giemsa e PAS - não permitiram a fácil identificação do E. cuniculi.

Palavras-chave: técnicas de coloração, cortes histológicos, Encephalitozoon cuniculi, microsporídios.

\section{ABSTRACT}

In this study, it was investigated different staining techniques applied to histological sections for identification of Encephalitozoon cuniculi. It was used liver fragments from Balb-c mice immunosuppressed with cyclophosphamide and inoculated with spores of Encephalitozoon cuniculi. The

\begin{abstract}
histological paraffin embedded sections were stained with hematoxylin-eosin (H-E), modified trichrome, GramChromotrope, Giemsa, Brown-Hopps, PAS, Ziehl-Neelsen, and Grocott and also by the technique of calcofluor. Toluidine bluefuchsin and toluidine blue stainings were used for the cuts embedded in plastic resin. Gram-Chromotrope, Brown-Hopps and Ziehl-Neelsen staining techniques permitted the best visualization of the spores for the diagnosis of $\boldsymbol{E}$. cuniculi in histological paraffin embedded sections, since they allowed the clear differentiation of the spores among other tissue structures. In tissues embedded in plastic resin, toluidine bluefuchsin and toluidine blue stainings also facilitate the finding of the agent. On the other hand, the trichrome technique showed great variability on results, therefore, allowing the identification of the parasite in tissue. The other techniques, H-E, calcofluor, Grocott, Giemsa and PAS did not permited the easy identification of the $\boldsymbol{E}$. cuniculi spores.
\end{abstract}

Key words: Encephalitozoon cuniculi, microsporidia, stain techniques, tissues sections

Os microsporídios são parasitos intracelulares obrigatórios, pertencentes ao filo Microsporidia, sendo identificados no tubo digestivo como agentes oportunistas, determinando diarréia persistente e perda de peso, ou ainda quadros de infecção generalizada, com o acometimento de diversos órgãos e tecidos. Encephalitozoon cuniculi é uma das espécies de microsporídios mais frequentemente observadas em infecções disseminadas (DIDIER, 2005). Técnicas de coloração específicas para os microsporídios têm sido rotineiramente empregadas

'Pós-graduação em Imunopatologia, Universidade Paulista (UNIP), Rua José Maria Whitaker, 290, Mirandópolis, 01425011, São Paulo, Brasil. E-mail: anetelallo@uol.com.br. *Autor para correspondência.

"Universidade de São Paulo (USP); Faculdades Metroplitanas Unidas (FMU), São Paulo, SP, Brasil. 
como métodos de triagem de amostras de fezes, urina, secreções respiratórias, entre outras, antes da utilização de diagnóstico molecular (THELLIER \& BRETON, 2008). Somente algumas dessas técnicas têm sido empregadas em tecidos, e uma análise comparativa e simultânea entre elas ainda não foi realizada em cortes histológicos, especialmente levando-se em consideração que existem variações de afinidades tintoriais entre as diferentes espécies de microsporídios (WEBER et al., 1992). Nesse sentido, o presente trabalho teve por objetivo comparar diferentes técnicas de coloração para a identificação de esporos de Encephalitozoon cuniculi em tecidos incluídos em parafina ou em resina plástica.

Foram utilizados camundongos isogênicos

Balb-c, livres de patógenos específicos $(S P F)$, machos, com 30 a 40 dias de idade, obtidos junto ao Biotério do Instituto de Biociência da Universidade de São Paulo (Brasil). Vinte animais foram imunossuprimidos com ciclofosfamida (Cy, duas doses semanais de $100 \mathrm{mg} \mathrm{kg}^{-1}$, por via intraperitoneal - IP) e inoculados por via IP com $10^{7}$ esporos de Encephalitozoon cuniculi. Foi mantido um grupo controle, com animais não imunossuprimidos e inoculados com $\boldsymbol{E}$. cuniculi. Os esporos de $\boldsymbol{E}$. cuniculi foram cultivados em células MDCK (Madin Darby Canine Kidney), conforme descrito por LALLO \& BONDAN (2005). Aos 35 dias de infecção, os animais foram eutanasiados pelo aprofundamento da anestesia geral e dois fragmentos de fígado foram fixados em solução de formol

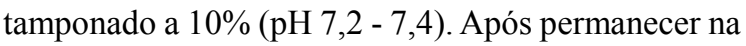
solução fixadora por 72 horas, os materiais foram incluídos em parafina e resina plástica (Technovit).

Os cortes histológicos incluídos em parafina foram montados em lâminas de vidro, desparafinados e corados pelas técnicas de hematoxilina-eosina (H-E), tricrômica modificada por WEBER et al. (1992), GramChromotrope (MOURA et al., 1996), Giemsa (RIJPSTRA et al., 1988), Brown-Hopps (SCHWARTZ et al., 1996), PAS (MARGILETH et al., 1973), Ziehl-Neelsen (TULI et el., 2010), Grocott (KWON-CHUNG et al., 1981) e calcoflúor (VÁVRA et al., 1993). As colorações azul de toluidina-fucsina e azul de toluidina (SCHWARTZ et al., 1996) foram utilizadas para os cortes incluídos em resina plástica. $\mathrm{O}$ projeto foi submetido e aprovado pelo Comitê de Ética e Pesquisa da Universidade Paulista (protocolo número 020/08).
O diagnóstico da microsporidiose em amostras teciduais pode ser difícil por várias razões, entre elas, pelo pequeno tamanho dos esporos (que variam de $0,9 \mathrm{a} 3 \mathrm{~mm}$ ) e pela presença do parasito sem resposta inflamatória tecidual. Adicionalmente, por meio da coloração H-E, os esporos apresentam-se fracamente basofílicos e distribuídos em pequeno número, de forma disseminada ou localizada, sendo facilmente ignorados (SCHWARTZ et al., 1994). Tal dificuldade de visualização dos esporos de $\boldsymbol{E}$. cuniculi pela técnica de H-E foi também observada em nosso estudo (Figura 1A).

Para investigar os microsporídios, WEBER et al. (1992) propuseram uma adaptação da coloração tricrômica utilizada na rotina dos exames parasitológicos, constituindo atualmente a técnica mais empregada para a pesquisa de microsporídios em excreções e secreções, embora sem ter sido até o momento testada em cortes histológicos. Empregandose essa coloração em amostras teciduais, os esporos de $\boldsymbol{E}$. cuniculi mostraram-se como estruturas ovoides com coloração rósea, medindo de 2,4 a $3,2 \mathrm{~mm}$ de comprimento por 1,6 a $1,7 \mathrm{~mm}$ de largura, com discreta variação de formato e tamanho (Figura 1B). A presença de um halo equatorial transparente, uma das características mais marcantes dos microsporídios, foi observada em apenas alguns esporos (Figura 1B). Quando os esporos apresentavam-se aglomerados, bem corados e no meio de uma reação granulomatosa, sua identificação no corte histológico tornava-se mais fácil do que quando isolados, pouco corados ou sem reação granulomatosa ao seu redor, uma vez que as células também apresentavam afinidade ao corante Chromotrope, mascarando a presença do parasito.

WEBER et al. (1992) empregaram as técnicas de Brown-Hopps e Brown-Brenn, as quais são adaptações da coloração de Gram, para detecção de esporos e de outros estágios intracelulares de microsporídios em tecidos fixados em formol. De forma idêntica aos autores anteriormente citados, constatouse que a técnica de Brown-Hopps permitiu a fácil evidenciação dos esporos de $\boldsymbol{E}$. cuniculi dentre outras estruturas teciduais (Figura 1C).

MOURA et al. (1996), por sua vez, submeteram amostras fecais positivas para microsporídios à coloração de Gram, substituindo o último passo, ou seja, trocando a passagem pela 


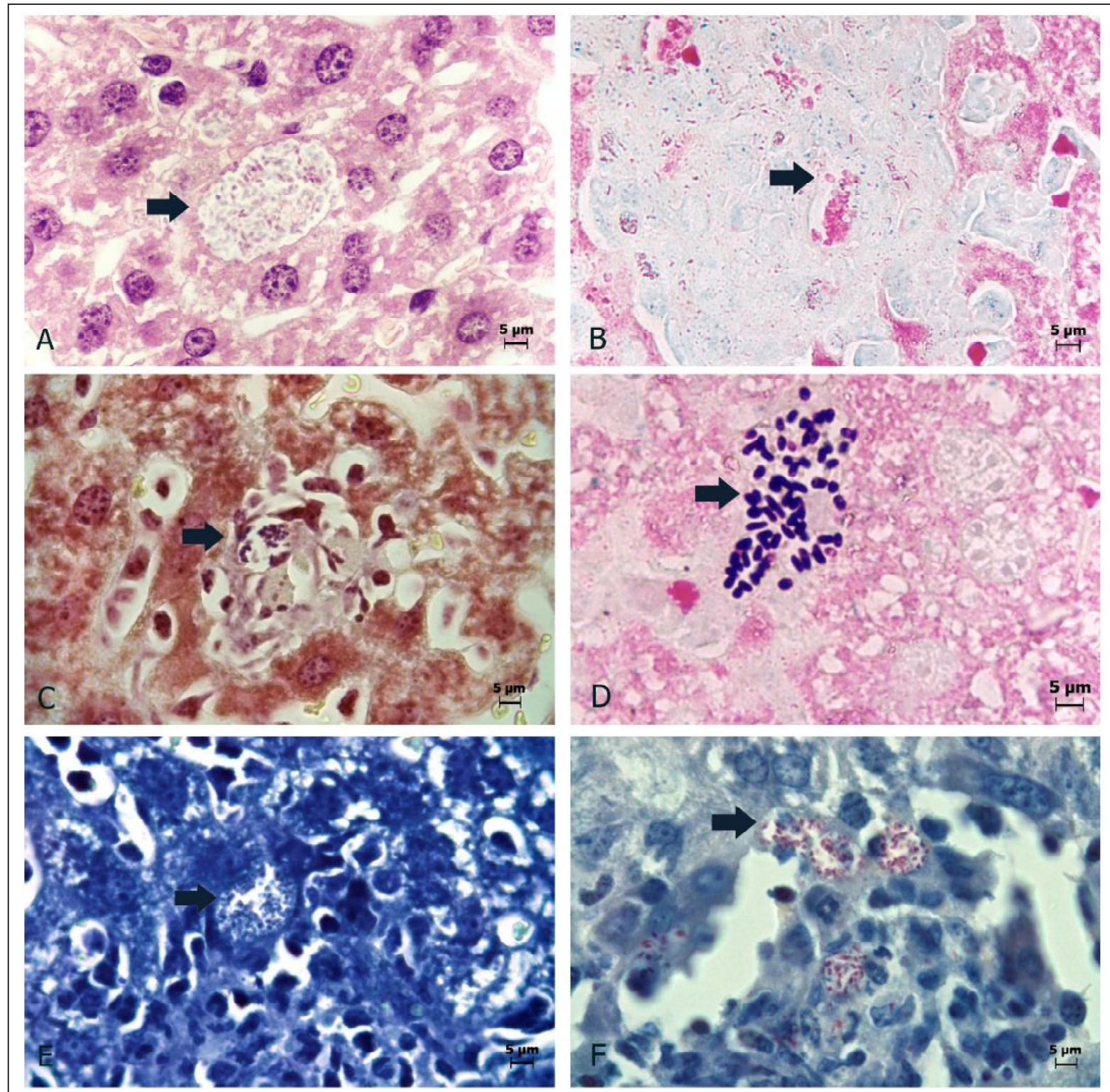

Figura 1 - Cortes histológicos de fígado incluídos em parafina. A. Coloração H-E - esporos fracamente basofílicos $(\rightarrow)$ ); B. Coloração tricrômica - esporos de coloração rósea em contraste com fundo levemente esverdeado, apresentando halo equatorial transparente $(\rightarrow)$; C. Coloração de Brow-Hopps - esporos de coloração púrpura em contraste com fundo amarelo $(\rightarrow)$; D. Coloração de Gram-Chromotrope - esporos de coloração púrpura ou violeta contrastando com o fundo levemente esverdeado ou transparente $(\rightarrow)$; E. Coloração de Giemsa - esporos fracamente corados $(\rightarrow)$; F. Coloração de Ziehl-Neelsen - esporos de coloração púrpura $(\rightarrow)$; Cortes histológicos de fígado incluídos em resina plástica. 1000x.

safranina pelo corante Chromotrope, preparado segundo WEBER et al. (1992). A técnica GramChromotrope modificada por MOURA et al. (1996) e empregada nos cortes histológicos permitiu identificar com clareza os esporos, que se apresentavam de coloração púrpura ou violeta, contrastando com o fundo róseo e ligeiramente esverdeado (Figura 1D). A presença do halo transparente ou pouco corado (róseo) na região central foi raramente observada.
A técnica de PAS, já utilizada para a identificação de Nosema e de outros microsporídios (MARGILETH et al., 1973), não permitiu, no presente estudo, a visualização dos esporos de $\boldsymbol{E}$. cuniculi. De acordo com MARGILETH et al. (1973), a adequação da técnica do do PAS parece depender da afinidade dos esporos das diferentes espécies de microsporídios ao corante. Essa diversidade na afinidade aos corantes também tem sido descrita para a coloração de Gram - 
enquanto que Encephalitozoon é fortemente positivo ao Gram, Enterocytozoon pode ser Gram-positivo ou negativo, exigindo maior atenção de quem está realizando o exame para a sua identificação (SCHWARTZ et al., 1994).

Assim como ocorre com outros parasitos, os esporos de $\boldsymbol{E}$. cuniculi mostraram afinidade ao corante de Giemsa. No entanto, o tecido também apresentou-se fortemente corado, não permitindo a identificação de imediato dos esporos. Dessa forma, mais tempo seria gasto para a realização do diagnóstico e, ainda assim, seu resultado poderia ser muitas vezes duvidoso (Figura 1E).

No presente experimento, utilizou-se a coloração de Grocott, que também tem como base a impregnação pela prata, porém os resultados não foram satisfatórios, uma vez que os esporos não se impregnaram com o corante e não foram evidenciados.

Assim como relatado por SCHWARTZ et al. (1996), observou-se também que os esporos de $\boldsymbol{E}$. cuniculi apresentaram afinidade aos corantes fucsina e azul de toluidina, tal como foi evidenciado nas colorações de Ziehl-Neelsen (Figura 1F), azul de toluidina (Figura 2A) e azul de toluidina-fucsina (Figura 2B), a primeira feita em tecidos embebidos em parafina e as duas últimas realizadas em tecidos incluídos em resina plástica. A observação dos esporos foi muito fácil, o que fortalece a indicação dessas três técnicas para o diagnóstico de microsporídios.

VÁVRA et al. (1993) utilizaram a coloração fluorescente de calcoflúor para o diagnóstico de microsporídios em esfregaços e em biópsias citológicas, observando que se tratava de um método de alta sensibilidade. DIDIER et al. (1995) compararam as técnicas de calcoflúor, tricrômica azul e imunofluorescência indireta e observaram que a coloração de calcoflúor, embora determinasse um grande número de falsos-positivos, possuía a vantagem de ser realizada em curto espaço de tempo e apresentar alta sensibilidade. Ao se utilizar a coloração de calcoflúor nos cortes histológicos, observou-se grande afinidade do corante aos tecidos, o que provocou intensa fluorescência inespecífica, impedindo, assim, a identificação dos esporos. Para as diferentes colorações testadas, não houve aparente diferença nos dados morfométricos obtidos da mensuração dos esporos de $\boldsymbol{E}$. cuniculi. Não foram observados esporos do parasito em cortes histológicos dos animais do grupo controle.

Entre as técnicas empregadas para o diagnóstico de $\boldsymbol{E}$. cuniculi em cortes histológicos incluídos em parafina, as que evidenciaram os esporos com maior clareza foram as colorações de GramChromotrope, Brown-Hopps e Ziehl-Neelsen. Para tecidos incluídos em resina plástica, as colorações de azul de toluidina-fucsina e azul de toluidina também possibilitaram fácil identificação dos esporos. Por fim, a técnica tricrômica mostrou grande variabilidade na coloração do $\boldsymbol{E}$. cuniculi, enquanto que as técnicas de H-E, calcoflúor, Grocott, Giemsa e PAS não permitiram que o parasito fosse identificado com segurança.

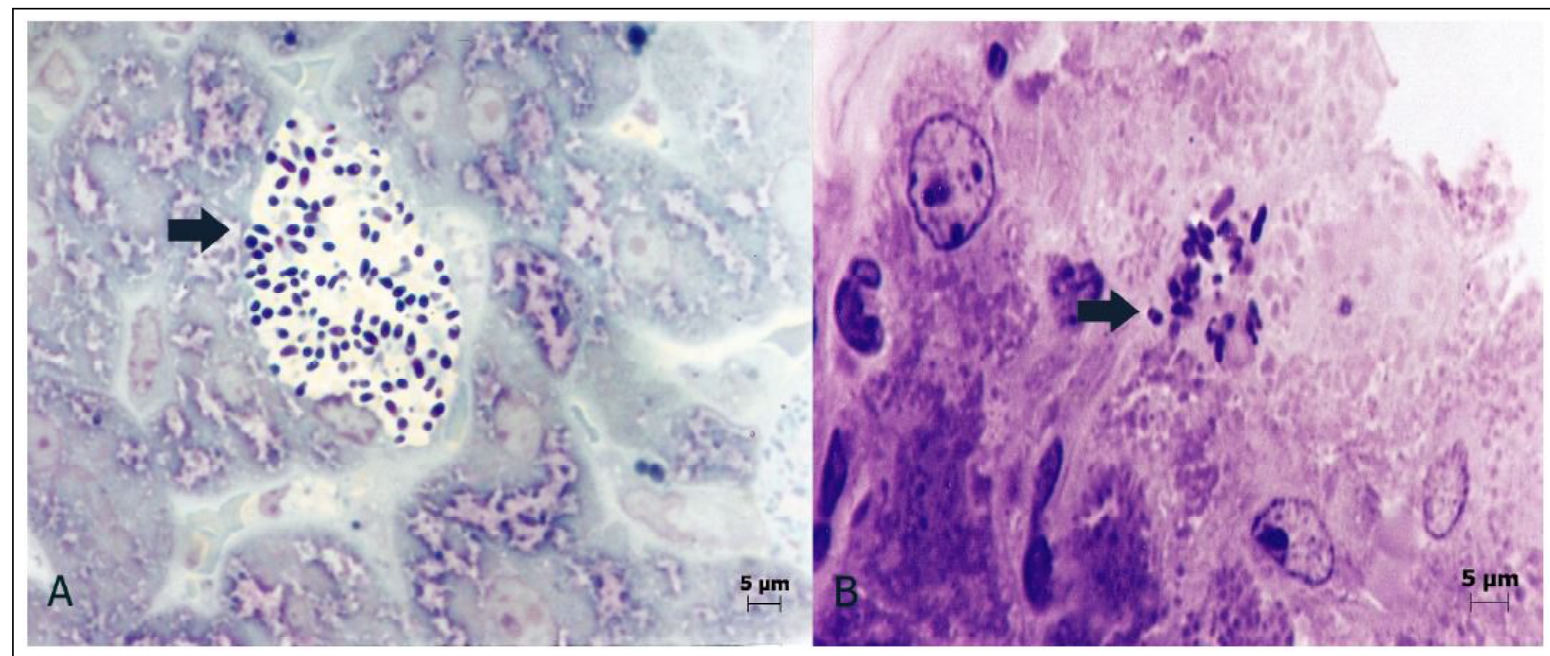

Figura 2 - Corte histológico de fígado incluído em resina plástica. A. Coloração de azul de toluidina - esporos corados em púrpura contrastados com fundo; B. Coloração de azul de toluidina-fucsina - esporos corados em azul-escuro. 1000x. 


\section{REFERÊNCIAS}

DIDIER, E.S. et al. Comparison of three staining methods for detecting microsporidia in fluids. Journal of Clinical Microbiology, v.33, p.3138-3145, 1995. Disponível em: $<\mathrm{http} / / / \mathrm{jcm}$.asm.org/cgi/reprint/33/12/3138>. Acesso em: 08 set. 2010 .

DIDIER, E.S. Microsporidiosis: an emerging and opportunistic infection in humans and animals. Acta Tropica, v.94, p.61-76, 2005. Disponível em: <http://www.sciencedirect.com/ science?_ob=ArticleURL\&_udi=B 6 T 1 R-4FJTP 7J$2 \&$ user $=687358 \&$ _coverDate $=04 \% 2 \mathrm{~F} 30 \% 2 \mathrm{~F} 2005 \&$ rdoc $=1$ \&_f $\mathrm{fm}=$ high\&_orig $=$ search\&_origin $=$ search\& sort $=\mathrm{d} \&$ docanch or $=\&$ view $=$ c \&_searchStrId $=1527082247 \&$ rerunO rigin $=$ google \&_acct $=$ C000037899\&_version $=1 \&$ urlVersion $=0 \&$ u s e r i d $=687358 \& \mathrm{~m} \mathrm{~d} 5=37$ e c 6255 e a $835 \mathrm{ca} 875 \mathrm{c} 3 \mathrm{e} 7 \mathrm{ecd} 3676 \mathrm{c} 77 \&$ searchtype $=\mathrm{a}>$ Acesso em: 08 set. 2010. doi:10.1016/j.actatropica.2005.01.010.

KWON-CHUNG et al. New, special stain for histopathological diagnosis of cryptococcosis. Journal of Clinical Microbiology, v.13, p.383-387, 1981. Disponível em: <http://jcm.asm.org/cgi/ reprint/13/2/383>. Acesso em: 08 set. 2010.

LALLO, M.A.; BONDAN, E.F. Experimental menigoencephalitis by Encephalitozoon cuniculi in cyclophosphamideimmunosuppressed mice. Arquivos de Neuropsiquiatria, v.63, p.246-251, 2005. Disponível em: <http://www.scielo.br/pdf/anp/ v63n2a/a10v632a.pdf $>$. Acesso em: 8 set. 2010. doi: 10.1590/ S0004-282X2005000200010.

MARGILETH, A.M. et al. Disseminated nosematosis in an immunologically compromised infant. Archives of Pathology, v.95, p.145-150, 1973.

MOURA, H. et al. Gram-chromotrope: a new technique that enhances detection of microsporidial spores in clinical samples. Journal of Eukaryotic Microbiology, v.43, p.94-95S, 1996. disponível em: <http://onlinelibrary.wiley.com/doi/10.1111/ j.1550-7408.1996.tb05019.x/abstract>. Acesso em: 8 set. 2010. doi: $10.1111 / \mathrm{j} .1550-7408.1996 . t b 05019 . x$.
RIPJSTRA, A.C et al. Use of light microscopy to diagnose small-intestinal microsporidiosis in patient with AIDS. Journal of Infectious Diseases, v.157, p.827-831, 1988.

SCHWARTZ, D.A. et al. Microsporidiosis in HIV positive patients: current methods for diagnosis using biopsy, cytologic, ultrastructural, immunological and tissue culture techniques. Folia Parasitologica, v.41, p.101-109, 1994. Disponível em: <http:/ /www.paru.cas.cz/folia/pdfs/showpdf.php?pdf $=21020>$. Acesso em: 8 set. 2010.

SCHWARTZ, D.A. et al. Pathology of microsporidiosis. Archives of Pathology \& Laboratory Medicine, v.120, p.173-188, 1996.

THELLIER, M.; BRETON, J. Enterocytozoon bieneusi in human and animals, focus on laboratory identification and molecular epidemiology. Parasite, v.15, p.349-358, 2008. Disponível em: <http://www.parasite-journal.org/dwld/ Parasite08-3_349-358_Thellier.pdf.>. Acesso em: 8 set. 2010.

TULI, L. et al. A multiattribute utility evaluation of different methods for the detection of enteric protozoa causing diarrhea in AIDS patients. BCM Microbiololgy, v.15, p.10-11, 2010. Disponível em: <http://www.ncbi.nlm.nih.gov/pmc/articles/ PMC2820438/pdf/1471-2180-10-11.pdf>. Acesso em: 8 set. 2010. doi:10.1186/1471-2180-10-11.

VÁVRA, J. et al. Staining of microsporidian spores by optical brighteners with remarks on the use of brighteners for the diagnosis of AIDS associated human microsporidioses. Folia Parasitologica, v.40, p.267-272, 1993. Disponível em: <http:/ /www.paru.cas.cz/folia/pdfs/showpdf.php?pdf $=21103>$. Acesso em: 8 set. 2010.

WEBER, R. et al. Improved light-microscopical detection of microsporidia spores in stool and duodenal aspirates. New England Journal of Medicine, v.326, p.161-166, 1992. Disponível em: <http://www.nejm.org/doi/pdf/10.1056/ NEJM199201163260304.>. Acesso em: 8 set. 2010. 